\title{
Kinh tế Việt Nam 2009 và một vài suy nghĩ về nhận thức luận chuyển đổi
}

\author{
Vương Quân Hoàng \\ Tạp chí Cộng sản \\ Vol. 81, No. 2 (Serial 807), 49-55 \\ * pi] Tap chi
}

(Jan. 15, 2010) 


\title{
KINH TÉ VIỆT NAM 2009 VÀ MỘT VÀl SUY NGHİ VẾ NHẬN THỨC LUẬN CHUYỂN DÖI
}

\author{
VUOONG QUÂN HOÀNG *
}

Việt Nam đang đứng trước ngưỡng cưa thập niên thứ hai, thế kỷ XXI. Tuy vậy, mốc thờ gian không quan trọng bằng nhũng đổi thay chóng măt của quả trình quốc tế hớ đời sống kinh tế, và những biến đổi sâu sắc nó sẽ mang lại. Quá trình ấy, ngay bây giờ, lại được phóng đại qua lăng kính của những biến động toàn cầu do khủng hoảng kinh tế - taii chính 2007 2009, điều cơ thể dẫn tới những biến đổi lớn về cấu trúc kinh tế nhân loai, cũng như diễn tiến địa - chính trị khăp noi trên thế giới.

\section{1 - Kinh tế Việt Nam năm 2009}

Dân số nước ta hiện nay xấp xỉ 85,9 triệu người, hiển nhiên là một quốc gia có dân số lớn của hành tinh khoảng 7 tỉ. Nếu như phần đông kinh tế gia quen với khái niệm bản chất của lạm phát là do quá nhiều tiền cạnh tranh nhau để giành về một số lượng quá ít hàng hóa, thì ở một nghĩa khác, nói như Min-tơn Frai-men (Milton Friedman), đó cũng có thể là quá nhiều người tìm kiếm một số lượng hàng hóa rất hữu hạn. Như vậy, dân số lớn, bên cạnh ưu điểm nguồn lao động dồi dào, chính là một câu hỏi lớn về khả năng cải thiện kinh tế.

Trong suốt hơn hai thập niên đổi mới, kinh tế Việt Nam liên tục duy trì đà tăng trưởng tương đối. Chất lượng mở rộng kinh tế thể hiện qua thống kê GDP bình quân đầu người từ mức 200 USD/người (năm 1986) đã tăng lên gấp 5 lần, đạt 1.000 USD/người vào năm 2008, và ước tính sẽ vượt 1.200 USD/người sau năm 2010. Sức hấp dẫn của nền kinh tế Việt Nam cũng thể hiện ở quy mô vốn đầu tư nước ngoài không ngừng tăng lên. Dù chịu ảnh hưởng từ các biến động kinh tế quốc tế, trở ngại của môi trường kinh doanh trong nước, sự gia tăng cạnh tranh thu hút nguồn lực từ các nền kinh tế đang phát triển trên thế giới, liên tục trong hai thập niên, tỷ lệ FDI so với GDP chỉ hai lần thấp hơn tăng trưởng GDP thực tế, vào các năm 1991 - 1993 và $2003-2007$ (xem hùnh 1). Lượng vốn FDI năm 2009 vần có được tín hiệu tốt, một cách so sánh so với bối cảnh

\footnotetext{
* TS, Đại học Tổng hợp Brúc-xen (Bỉ)
} 
khu vực, với mức cam kết mới 20 tỉ USD, và phần giải ngân lượng cam kết quá khứ để cấu thành nguồn lực thực tế 8 tỉ USD.

Hinh $1-T y ̉$ lẹ FDI/GDP và tăng truớng GDP thuc tế

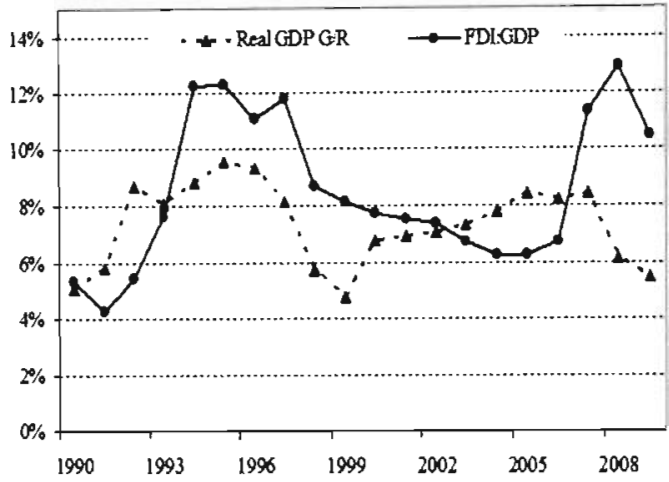

Nguồn: GDP, FDI theo giá hiện tại, Tổng cuc Thống kê

Tăng trưởng kinh tế là một trong những mục tiêu ngắn và trung hạn để giải tỏa áp lực này. Trong một bối cảnh khó khăn của kinh tế toàn cầu như năm 2009, tăng trưởng theo quý của Việt Nam được xem như một nỗ lực có kết quả, với Quý I tăng 3,14\%, Quý II tăng $4,46 \%$, Quý III tăng 5,76\% và ước Quý IV tăng $6,8 \%$. Với mức tăng trưởng này, nền kinh tế đã tạo ra được hơn 1,5 triệu việc làm trong năm 2009, và đây là một con số có rất nhiều ý nghĩa, nếu so sánh với con số gần 800 tỉ USD mà nước Mỹ phải chi ra để cún vãn tình trạng thất nghiệp - một trong những vấn đề nghiêm trọng và đáng sợ nhất của nền kinh tế thị trường - trong khi tình trạng thất nghiệp tại Mỹ vẫn ở mức hai con số.

Một trong những chương trình kinh tế lớn của năm 2009 là triển khai gói kích thích kinh tế và an sinh xã hội trên quy mô toàn quốc, có giá trị tiền tệ ước tính 100.600 tỉ đồng, với vai trò rất quan trọng của: (1) Hệ thống ngân hàng thương mại là bơm hơn 418.000 tỉ vốn ngắn - trung hạn có hỗ trợ lãi suất tới hệ thống sản xuất - dịch vụ của nền kinh tế (xem hình 2); (2) Hệ thống tài chính chính phủ tăng cầu qua 20.000 tỉ miễn giảm thuế; (3) Hệ thống đầu tư nhà nước, với 60.800 tí; và, (4) Chi thường xuyên cho an sinh, khoảng 9.800 tì.

Hinh 2 - Tồn luợng tín dụng theo chuoong trình hỗ trợ lãi suất

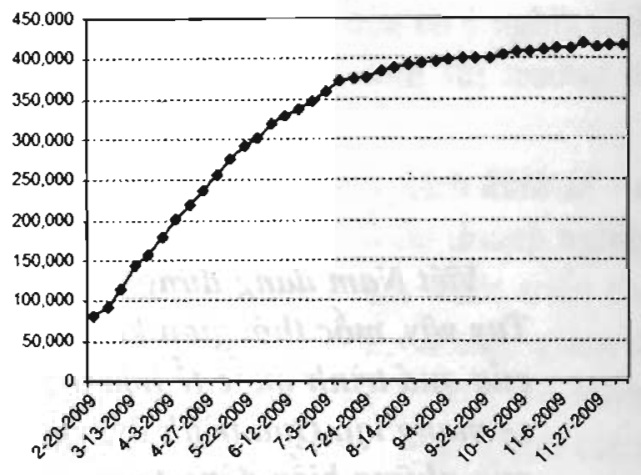

Về hiệu suất triển khai, chương trình có thể coi là thành công trước mắt từ thực tế ngăn chặn đà suy giảm kinh tế, quá trình tạo việc làm mới, cũng như sự phục hồi niềm tin của dân cư và nhà đầu tư ở một số thị trường tài sản. Sản xuất công nghiệp và tiêu dùng xã hội được hồi sinh, ít ra là thoát khỏi sự yếu ớt ở quý IV-2008 và Quý I-2009. Điều này đặc biệt có ý nghĩa khi lạm phát ở múc ước tính cả năm 7\%; và chỉ có một loại "lạm phát phấn khích" đã từng xuất hiện trong khoảng thời gian 4 - 5 tháng giữa năm 2009 : tăng giá tài sản tài chính. Sau khi rớt đáy vào cuối tháng 2-2009 (VN Index: 235,5 và HNX Index: 78,6), các thị trường chứng khoán tại Thành phố Hồ Chí Minh và Hà Nội đều đã tăng mạnh, lần lượt là $165 \%$ và $180 \%$. Mặc dù xuất hiện sụt giảm từ cuối tháng 10 , các chỉ số chứng khoán về cuối năm vẫn giữ mức tăng trưởng vài chục phần trăm (hình 3). 
Hinh 3 - Biến động các chỉ số chứng khoán Việt Nam năm 2009

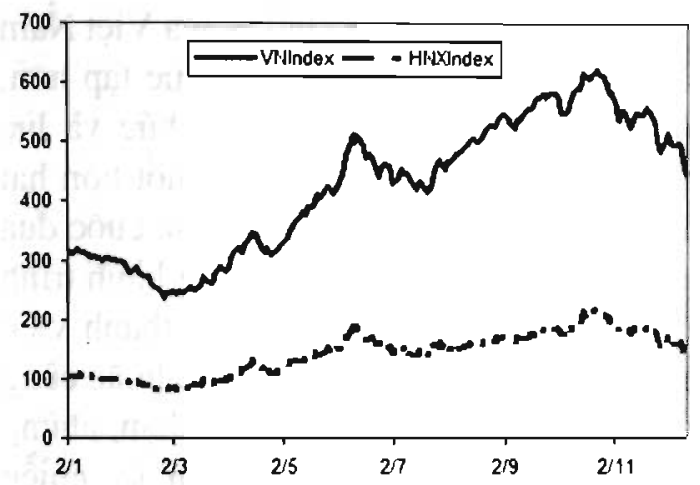

Nguồn: Dan Houtte, Vuong \& Partners

Có thể nói, một phần sức khỏe của nền kinh tế được phục hồi nhờ những nguồn lực bổ sung nói trên, và cũng cần công nhận sự chèo lái bền bỉ của hơn 300.000 doanh nghiệp (theo số thống kê) cũng như hàng triệu hộ gia đình nỗ lực giải quyết sức ép của suy giảm thu nhập thực tế bằng vô số phương cách mà không chính sách vĩ mô nào soạn thảo ra được.

Tuy vậy, cũng có những con số khiến chúng ta không thể không lo ngại. Thâm hụt ngân sách tăng lên mức cao trong lịch sử, $6,8 \%$ GDP. Số người nghèo - theo chuẩn của chúng ta - vẫn ở mức $11 \%$, mặc dù đã giảm. Sự ám ảnh của nhập siêu đã quay lại với mức 11,54 tỉ USD; như thế, kỳ vọng khống chế dưới 10 tỉ USD nay đã lại là con số quá khứ, và tới hơn 1 tỉ USD cho nhập hàng công nghệ xa xỉ như ô-tô. Trong khi đó, nỗi lo suy giảm xuất khẩu đã thành sự thật, đứng ở mức xấp xỉ 50 tỉ USD, giảm $15 \%{ }^{(i)}$.

Sức khỏe nền kinh tế hiển nhiên không thể chỉ đo bằng vài con số thô sơ, khi mà ngay cả dấu hiệu sức cạnh tranh hàng hóa Việt ngay tại thị trường Việt Nam cũng đủ để xã hội lo lắng. Đó là chưa kể hệ thống an sinh vật chất lẫn tài chính còn ở trình độ rất thô sơ, và mỗi sự cải thiện đều cần can thiệp trực tiếp từ Chính phủ, từ số giường bệnh, phòng học đến những khoản trợ cấp vùng nghèo hay bão lự. Nói cách khác, nền kinh tế vẫn đang thiếu hụt những nền móng xã hội cho một công cuộc lấy sức chạy đua trên đường dài.

Bản thân quá trình phục hồi kinh tế, cũng chứa đựng những mối âu lo của năm 2010 , và cả những năm sau. Lượng tín dụng biểu hiện trong hình 2 cho thấy, việc tiệm cận mức rủi ro mà nền kinh tế có thể chấp nhận, trước cân nhắc lạm phát và rủi ro nợ khó đòi trong tương lai của hệ thống ngân hàng. Trên thực tế, vẫn còn 7.000 tỉ đồng hỗ trợ lãi suất, nhưng hiệu lực thực tế của hỗ trợ này đã suy giảm từ khoảng tháng 10-2009, do khuynh hướng lãi suất, tình hình sử dụng vốn và tính khó nắm bắt của hiệu quả tài sản kinh doanh hình thành từ nguồn vốn trợ cấp. Trí nhớ của thị trường chưa kịp xóa đi những ám ảnh về tín dụng và thanh khoản của hệ thống ngân hàng cuối năm 2007 - đầu năm $2008^{(2)}$. Không có gì khó hiểu khi Quốc hội đặt câu hỏi về sự công bằng và tính hiệu quả vào kỳ họp cuối năm 2009. Sự phục hồi rất mong manh, và cần nhiều hơn chỉ một nguồn tín dụng mang tính trợ cấp, vốn cũng đi ra từ nguồn thu của chính nhân dân.

\section{2 - Nhận thức về vận động kinh tế}

Sau 23 năm đổi mới, nước ta cũng chỉ mới bước đầu trên hành trình tìm kiếm phương tiện cho mục tiêu thịnh vượng. Xét cho cùng, hành trình ấy là của hàng triệu cư dân, và cũng bắt đầu từ lịch sử xa xôi. Vân Đồn, Phố Hiến, Kẻ Chợ hay Đà Nẵng, Hội An, từ thế kỷ XVII đã nằm trong ký ức lịch

(1) Số liệu ước tính cho lởi hết tháng II-2009

(2) Vương Quân Hoàng: Nhìn lại nền kinh lế Việt Nam 2008 phải trong bối cảnh khủng hoảng tài chinh thế giới. Tạp chí Cộng sản điện tử số 2 (170), tháng 1-2009 
sử thương nhân khu vực và châu Âu như điểm đến của cơ hội kinh tế. Ở đó, các giao dịch không chỉ phản ánh lợi ích và hành vi giao thương, mà con người và hàng hóa Việt Nam đã từng là lực lượng khẳng định hành trình tìm kiếm sự thịnh vượng. Kể cả trước đó nữa, thì sự hồi sinh kinh tế của Thăng Long dưới triều Vua Lê Thánh Tông (1449 1497) cũng phản ánh phần lớn qua cơ cấu kinh tế "36 phố phường" của sản xuất, dịch vụ và giao thương.

Điều chúng ta có thể nhìn thấy từ hành trình này là một quy luật chung về tự do kinh doanh, bao gồm cả quyền sở hữu tài sản cá nhân, và quyền được tôn trọng sự độc lập kinh tế của cá thể, nhóm. Các kết cục chung của những thời kỳ thịnh vượng - thường khiến chúng ta tiếc nuối - lại có nguyên nhân nói chung đơn giản. Đó là khi quyền sở hữu tài sản cá nhân bị tước đoạt, sự can thiệp khiến tự do và độc lập kinh tế cá nhân chỉ còn là hình thức, và sức ép chi tiêu trước mắt khiến cho các xã hội, bao gồm cả nhà nước, dồn hết nguồn lực cho tiêu dùng ngắn hạn. Nói như cách hiểu của giới kinh tế về ràng buộc ngân sách là sự sẵn sàng chiết khấu giá trị của tương lai để tiêu dùng hiện tại. Hiển nhiên, điều này không chỉ xảy ra với một quốc gia cự thể như Việt Nam trong thời kỳ hơn 2.000 năm phong kiến. Nước Pháp chỉ với đồng tiền Franc vàng, cũng đã có biến đổi từ Vua Charles V (1364 - 1390), khi ấn định một Franc vàng (Franc-à-cheval) là 3,83 gram vàng đã rút giá trị xuống 0,29 gram thời Louis XVI, một hình thức kiếm lợi từ việc giảm giá trị đồng tiền mà giới nghiên cún gọi là sei-ni-o-rei (seigniorage). Bản thân triều Nguyễn, trước khi vua Tự Đức đầu hàng chịu sự bảo hộ của Pháp, cũng đã xảy ra những quâ trình kinh tế suy thoái, phần nào có nguồn gốc từ sự ra đi của những lực lượng thương mại trứ danh, vốn đã làm phồn thịnh các cảng biển giao thương của Việt Nam từ thế kỷ XVI ${ }^{(3)}$.

Cho tới lúc này, nền kinh tế của Việt Nam đã và đang ngày một trở nên phức tạp hơn, với các cơ chế, thị trường, tổ chức và lực lượng kinh tế mới ra đời trong suốt hơn hai thập niên đổi mới. Sự gấp gáp của cuộc đua tranh kinh tế được nhân lên bằng hành trình hội nhập, trong đó Việt Nam là thành viên mới của WTO. Hoặc ngẫu nhiên, hoặc cũng có thể là tác động nhân quả ngắn hạn, những năm đầu gia nhập WTO là thời kỳ nhiều sóng gió cho nền kinh tế thị trường non trẻ của chúng ta. Chỉ khi đứng trước những biến cố lớn - và nhận thức rõ sự hạn chế phương pháp tư duy, chiến lược phát triển kinh tế trong lúc đó - ta mới tự thấy hiểu biết hạn chế đến thế nào về chính những khái niệm kinh tế thị trường mà cả xã hội đã hào hứng "học từ vựng" trong hơn hai thập niên qua.

Điều khó của từ vựng không nằm ở bản thân nghĩa của từ, mà nằm ở hệ thống nhận thức luận về các quá trình đang diễn ra và chi phối chúng. Khi quá trình thay đổi, nghĩa của từ cũng thay đổi. Một hình ảnh mô phỏng có thể minh họa là khi các thị trường thế giới đang tìm cách đánh giá lại giá trị đồng USD, thì cũng là lúc nhận thức về hành trình ưu việt của nền kinh tế $\mathrm{Mỹ} \mathrm{bị} \mathrm{rung} \mathrm{lắc}$ mạnh.

Quá trình của Việt Nam, cho dù là nền kinh tế rất nhỏ bé so với thế giới, cũng không kém phần phức tạp, đó là vì chúng ta còn có thêm một yếu tố bổ sung mang tên "Quá trình chuyển đổi". Quá trình này đã đem lại những lợi ích cụ thể cho đời sống

(3) Ở thế kỷ XVI, theo lời một số giáo sĩ châu Âu, kinh thành Thăng Long là đô thị giao thương sầm uất không thua kém nhiều thành phố lớn châu Âu, lúc đó đang trên đà phục hưng và chuẩn bị cho một cuộc cách mạng khoa học - công nghệ thời kỳ sau đó 
kinh tế quốc gia, tuy nhiên trong các bản báo cáo thành tích thường ít đem lại gợi ý cho một lý thuyết tương lai. Chúng ta cần một bức tranh mang tính phân tích sâu sắc hơn một báo cáo.

Bên cạnh những thành tựu - mà độc giả đều thường xuyên được cập nhật sớm - thì độc quyền có lẽ là phần bức tranh méo mó nhất của quá trình chuyển đổi, điều mà chính các nền kinh tế tư bản - xây trên móng vận hành thị trường nhiều thế kỷ, với những phép biến đổi lịch sử rất căn bản - luôn phải đối phó bằng cả luật pháp lẫn đạo đức. Tuy vậy, độc quyền ấy đang diễn ra vừa công khai vừa âm thầm trong nền kinh tế Việt Nam, và tác động ngày một mạnh hơn lên diễn biến kinh tế, thông qua các lợi ích nhóm - về cơ bản là "cận thị" và mang tính phá hủy - có thể dễ dàng quan sát thấy bởi các triệu chứng giá, điều tiết nguồn cung, từ bỏ các cam kêt vốn là nguồn gốc để độc quyền được đặt vào tay họ (ví như Tập đoàn Điện lực Việt Nam từ chối xây nhà máy điện hay cắt bỏ các dây cáp viễn thông của VNPT do tranh chấp về giá thuê cột), mà mục tiêu cuối cùng cũng chỉ là khái niệm rất gần gũi: Tô kinh tế độc quyền. Bản thân $\mathrm{C}$. Mác đã dành rất nhiều công sức để chỉ rõ về mặt nhận thức tác hại của các loại tô, mà những kinh tế gia hiện đại nhất, cổ vũ thị trường tự do, bao gồm cả chính sách tự do kinh doanh (laissez-faire), cũng thừa nhận rằng đánh thuế $100 \%$ tô kinh tế cũng không tác động gì tới cấu trúc và hiệu suất nền kinh tế. Nhưng giờ đây, chúng tồn tại khắp nơi, hiển hiện và ở quy mô lớn tới mức gây ra sự đột biến về chênh lệch thu nhập, lợi tức mà các nhà tư bản kếch sù nhìn thấy ở Việt Nam cũng phải thèm thuồng. Đất đô thị, đất chuyển mục tiêu kinh doanh, dầu mỏ, khoáng sản, và cả bản thân tư bản... là mục tiêu khai thác tô kinh tế của các tập đoàn.
Các đại biểu Quốc hội vẫn tiếp tục chất vấn về hiệu quả đầu tư khi ICOR liên tục tăng và đạt 8 lần vào năm 2009 (xem bảng 1 ). Quan điểm của $\mathrm{Ri}$-cac-đô về tăng đầu tư để hy vọng tăng sản lượng đã được thực tế chứng minh không hiệu quả. Trong bối cảnh thế giới cũng đang đứng trước thách thức tìm kiếm mô hình phát triển bền vững mới, hướng đi kinh tế tri thức, sáng tạo càng trở nên cần thiết và quan trọng theo nguyên lý khởi nghiệp với giả định nguồn lực không có sẵn từ trước.

Bảng 1: ICOR qua các giai đoạn

\begin{tabular}{|c|c|}
\hline Giai doạn & ICOR \\
\hline $1991-1995$ & 3,50 \\
\hline $1996-2000$ & 4,80 \\
\hline $2000-2003$ & 5,24 \\
\hline $2004-2006$ & 5,04 \\
\hline $2007-2008$ & 6,15 \\
\hline 2009 & 8,00 \\
\hline
\end{tabular}

Nguồn: Tổng cuc Thống kê, năm 2009

\section{3 - "Sự phá hủy mang tính kiến tao"}

C.Mác là một thiên tài, với trí lực không chỉ kiệt xuất mà gần như có thể nói là toàn diện, đã đi trước thời đại của ông nửa thế kỷ khi đặt nền móng cho lý thuyết chu kỳ, với những tiên liệu về khủng hoảng. Điều mà chúng ta muốn mượn từ trí lực của C.Mác chính là quan điểm biện chứng lịch sử về quá trình cạnh tranh và phá bỏ chính những nền móng phôi thai một phần cơ thể của kinh tế thị trường, rồi tiếp tục xây dựng mới. Bản thân C.Mác, với trí tuệ thiên tài, đã nói rất rõ trong Tuyên ngôn của Đảng Cộng sản rằng hệ thống kinh tế thị trường đã mang lại những thành tựu công nghiệp, kinh tế, đô thị và sức sống mà hàng triệu năm lịch sử loài người không tiến tới được. Đó là quá trình 
mà nhà kinh tế lỗi lạc của thế kỷ XX, Schăm-pít-tơ (Schumpeter) gọi là "Sự phá hủy mang tính kiến tạo"(4).

Đối với ý nghĩa của "Sự phá hủy mang tính kiến tạo" chúng ta đều hiểu sự chuyển dịch gì xảy ra khi 4 chữ cuối bị cắt bỏ. Bản thân Schăm-pít-tơ, cha đẻ của thuật ngữ làm thay đổi cách nghĩ của thế giới về các quá trình thị trường, về cơ bản cũng đồng ý với C.Mác về cái đích đi đến của chủ nghĩa tư bản - là sự chấm dứt và thay thế nó - thông qua bản thân cái mà ông gọi là con bão dồn dập, không ngừng nghỉ của sự phá hủy và tái tạo; một quá trình tự nó cũng có cái bẫy của sự gián đoạn tái tạo, hoặc bản thân cán cân đó nghiêng về phá hơn là xây.

Quá trình này đang diễn ra trong nền kinh tế của Việt Nam, và mạnh mẽ hơn qua năm 2009 , cho dù những kết quả sàng lọc có thể chưa được thống kê. Bản chất sự chuyển đổi kinh tế đã gắn liền với chuyển đổi sở hữu tài sản vốn và vật chất, gắn liền với chúng là lợi ích kinh tế. Như vậy, câu hỏi lớn về phúc lợi kinh tế toàn thể, trước sau cũng đặt ra câu hỏi về số phận tài sản sẽ nằm trong tay một số nhỏ những người rất giàu có của chính Việt Nam, và quá trình phân phối tài sản trong thu nhập quốc dân.

Tầng lớp tư sản thị thành đang tăng lên nhờ những tích lũy tài sản chủ yếu là tư bản và bất động sản, nhưng quá trình tiêu dùng kiểu "hiệu ứng Du-e-sen-bơ-ri (Duesenberry)" (nhà kinh tế Mỹ James Duesenberry) đang góp phần biến đô thị thành nơi tạo ra sự bất bình đẳng và nhập siêu cho lối sống xa hoa; với những thanh niên con nhà giàu một đêm đốt cả năm lương của một công chức lương thiện cho giải trí, hay những thú tiêu dùng sùng bái vật chất tới mức một chiếc xe hợ có thể là lượng tư bản đủ kiến tạo 3 - 4 nhà máy hạng vừa. Nếu hời hợt cho rằng đó là sự tất yếu của kinh tế thị trường và thừa nhận không cần suy xét thêm, thì cũng đồng nghĩa với việc sẵn sàng trượt vào vết xe tiêu dùng không tích lũy, mất cân bằng trong cả tăng trưởng lẫn tiến bộ của trạng thái kinh tế; điều mà ít nhiều quá trình phá kỷ lục nhập siêu liên tục cả thập kỷ vừa rồi mách bảo mỗi người từ tiềm thức.

Rõ ràng nhập siêu không bắt buộc phải gắn liền và càng không phải là nguyên nhân tạo ra tăng trướng, tiến bộ của nền kinh tế thị trường - qua trường hợp của Trung Quốc suốt vài thập niên qua, hay trước đó là Nhật Bản, Hàn Quốc. Hàng hóa tư bản nhập khẩu cũng không bảo đảm sự phát triển thành công của sáng tạo công nghệ và khai thác các cơ hội chiến lược, giống như lịch trình công nghệ ti-vi của Việt Nam vẫn chỉ đem lại sự độc lập ở chiếc hộp các-tông hay hơn nữa thì là lớp bọc xốp. Khái niệm giá trị lao động kết tinh vay mượn của C.Mác, nếu được bóc tách bằng lượng gia tăng nội địa, chỉ giúp chúng ta kết luận về sự thua kém thảm hại năng suất và chất lượng lao động giữa cái được kết tinh ở đây, với cái được thị trường thừa nhận trong nhà máy của Sony hay Toyota mà thôi.

Như vậy, trong hành trình kinh tế dù là đi đến thịnh vượng dài hạn, hay là đi qua thời kỳ chuyển đối thành cổng - để trở thành một quốc gia công nghiệp năm 2020 - như các nhà hoạch định đã đặt ra, thì một công việc sống còn vẫn là hệ thống lý thuyết kinh tế dẫn đường cho không chỉ tăng trưởng, mà cả phát triển và tiến bộ.

Ở trong bối cảnh của Việt Nam, và dựa trên những nhận thức luận về tiến trình kinh tế lâu dài của lịch sử đương đại, có thể nhìn thấy được một cột trụ quan trọng bậc nhất của nó là hệ thống lý thuyết về khởi nghiệp, mà từ những năm cuối thập niên 90 thế kỷ $\mathrm{XX}$,

(4) Nguyên văn "The perennial gale of creative destruction," ông viết trong cuốn sách kinh điển Capitalism, Socialism and Democracy, Harper \& Brothers, 1942 
bắt đầu nhận được sự quan tâm nhiều hơn thông qua các chương trình hỗ trợ kỹ thuật và tài chính cho khối doanh nghiệp vừa và nhỏ (thường gọi tắt là SME). Tuy nhiên, nền kinh tế khởi nghiệp không chỉ giới hạn trong phạm vi SME mà thôi, mà những quốc gia rất phát triển như Ca-na-đa đã mở rộng biên giới của lý thuyết khởi nghiệp tới tận bộ máy chinh phủ, theo những phương cách nghiên cứu kỹ lưỡng và đã rất thành công. Trên thực tế, không ở khu vực nào trong nền kinh tế mà tính sáng tạo, sự tiến bộ công nghệ và tích tụ lại có thể hiệu quả hơn khu vực ngự trị bởi tinh thần khởi nghiệp.

Thị trường thiếu vắng những cơ hội tạo giá trị mới - đầu ra của quá trình khởi nghiệp là môi trường thuận lợi cho phát triển các hành động đầu cơ. Cảnh đông đúc tại các tiệm vàng, cửa hàng thu đổi ngoại tệ trong những ngày biến động giá vàng và USD của tháng 11 vừa qua thể hiện rõ ràng nỗ lực tìm kiếm lợi nhuận ngắn hạn, đồng thời với trú ẩn tài sản ${ }^{(5)}$. Liên thông chứng khoán, bất động sản, tín dụng đã mở rộng sang các thị trường thanh khoản linh hoạt hơn là vàng và ngoại tệ ${ }^{(6)}$. Hiện tượng bất thường này được nhà kinh tế học người Áo Lút-vích Vôn-misơ (Ludwig Von Mises) lý giải như hành động hợp lý của mỗi con người kinh tế. Trong đó, cá nhân giao dịch vội vã tới mức không kịp quan sát các điều kiện thị trường thay đổi cũng như dự báo kết cục thị trường trước hành vi đồng nhất của đám đông. Họ đặt $d u$ tính kiếm lợi và tránh mất mát tài sản lên trên hết.

Khởi nghiệp, như một quá trình phức tạp và đồng bộ, có ảnh hưởng quan trọng tới sự thịnh vượng và ổn định của nền kinh tế trong dài hạn. Nhưng chính cộng đồng doanh nhân khởi nghiệp Việt Nam cũng có những vấn đề, tiềm ẩn hay rõ ràng, tác động tiêu cực tới hành trình kinh tế tương lai. Đó có thể là mô hình kinh doanh dựa trên tìm kiếm đặc lợi kinh tế (rent-seeking), quan hệ tín dụng với ngân hàng bằng quan hệ cá nhân, và những hệ quả từ hệ thống giáo dục kinh doanh coi trọng hình thức và bằng cấp. Trong trào lưu chứng khoán hóa, thâu tóm - sáp nhập (M\&A) doanh nghiệp, một bộ phân doanh nhân khởi nghiệp đang dịch chuyển vai trò từ người chủ doanh nghiệp sang nhà quản lý hưởng lương - khởi nguồn của vấn đề xung đột lợi ích đại diện, và từ người khởi nghiệp thuần túy sang nhà tư bản. Các định chế thị trường thúc đẩy quá trình tách biệt sở hữu và kiểm soát phân định rạch ròi giữa nhà tư bản không khởi tạo kinh doanh và người khởi nghiệp không sở hữu tư bản. Khi kinh doanh thất bại, nhà tư bản mất tiền vốn đầu tư. Người khởi nghiệp chịu rủi ro với phần vốn chính họ bỏ ra, thường là khoản đầu tư (nhỏ tuoong dối so với nhà tu bản) từ tích lũy cá nhân để ươm mầm kinh doanh ban đầu. Bởi vậy, không nên kỳ vọng năng lực chấp nhận rủi ro đặc biệt ở những người khởi nghiệp. Kinh tế khởi nghiệp bác bỏ quan niệm "rủi ro cao, lợi nhuận cao". Lợi nhuận là phần thưởng dành cho khả năng nhận thức nhanh nhạy của người khởi nghiệp trước các cơ hội tạo giá trị, chứ không phải các hành vi kinh tế mạo hiểm.

Một nghị sự cho khởi nghiệp có lẽ đáng được coi là cấp thiết và quan trọng bậc nhât cho 2010, thay vì con số GDP hay lượng vốn cần cấp cho các tập đoàn nhà nước. Cuối cùng thì sức mạnh kinh tế vẫn nằm trong tay của hàng triệu người lao động, và được thể hiện qua sức phát triển bền bỉ, quy mô và sự đa dạng của hệ thống khởi nghiệp trong nền kinh tế. $\square$

(5) Trong 3 giờ đồng hồ, từ $9 \mathrm{~h}$ đến $12 \mathrm{~h}$ sáng ngày 11-11-2009, giá vàng trên thị trường trong nước liên tục tăng lên với mức chênh lệch cao nhất 3 triệu đồng/lượng

(6) Vương Quân Hoàng và Nguyễn Hồng Sơn: Về mối liên thông giữa thị truờng bất động sản, vốn và tiền tệ, Tạp chí Cộng sản số 785, tháng 4-2008 